\title{
Multi-Criteria Optimization of the Heat Energy Sources Structure
}

\author{
Olga A. Edeleva \\ Melentiev Energy Systems Institute of Siberian Branch of \\ the Russian Academy of Sciences \\ Irkutsk, Russia \\ edel@isem.irk.ru
}

\author{
Valery A. Stennikov \\ Melentiev Energy Systems Institute of Siberian Branch of \\ the Russian Academy of Sciences \\ Irkutsk, Russia \\ sva@isem.irk.ru
}

\begin{abstract}
In the article multi-criteria problem of optimization of heat energy sources is formulated, which provides reliable and safe heat supply to consumers with minimal impact of heat supply facilities on the environment. There are two stages of its solution. Firstly, via decomposition method the problem is divided into two sub problems. Secondly, via the weighting coefficients method and the $\varepsilon$-constraints one these sub problems reduce to finding a single criterion. The algorithm of the problem solution by the $\varepsilon$ constraints method is described. Application of the proposed methods to a real case of heat supply system is given.
\end{abstract}

Keywords- heat source, heat supply system, critical infrastructure, air pollution, multi-criteria optimization.

\section{INTRODUCTION}

Heat supply systems (HSS) of urban areas are one of the most important critical infrastructures of the energy and economy sector [1], since disruption of their work may entail a heat shortage which may affect the social and economic activities and lead to disaster dangerous toinhabitants.

On the other hand, the objects of heat supply systems are technologically dangerous industrial ones because of high pressure and temperature of energy carrier [2]

The article is devoted to a problem that integrates two goals: to provide reliable and safe heat supply of consumers with the lowest cost and to minimize impact of heat sources on the atmosphere.

There are three levels of development and optimization of heat sources: synthesis, design and operation [3]. Since these levels are mutually dependent, global optimal solutions can only be obtained if all three levels are considered together.

Thus, the purpose of optimization is to identify the optimal level of synthesis and the optimal size and composition (design level) of heat sources while simultaneously taking into account the effective operation of the selected equipment [4].

The problems of building and optimizing heat source options are multi-purpose. For example, minimizing costs and environmental loads are usually conflicting goals, because often environmentally friendly technologies are expensive $[5,6]$.

We call such goals criteria which determine in their totality the directions of development of heating systems. In addition to the above, criteria can also be reliability of energy supply, quality of heat energy, fuel volumes, etc .

The traditional approach to solving such multipurpose problems of energy supply [7-10] is usually to reduce them to a single-criterion problem by highlighting the main criterion and translating the other criteria into the category of constraints. This is justified if it is possible to assign such criteria in the form of relevant standards (for example, equipment reliability, minimization of the level of air pollution, etc.).

Below, we will consider ways to solve a multicriteria problem of optimizing the structure of heat sources during the development of HSS, based on decomposition and application of two methods of reducing this task to a single-criterion one.

The structure of heat sources correspond to the type and composition of equipment, capacity and number of sources and their territorial distribution.

\section{MULTI-CRITERIA OPTIMIZATION OF THE HEAT SOURCES STRUCTURE}

The multi-criteria optimization problem of the type and basic parameters (structure) of heat sources can be presented as a set of criteria:

$$
\begin{aligned}
& \gamma=\left\lfloor S_{z}, S_{n e t}, E_{k}, R_{j}\right\rfloor, \\
& S_{z}\left(Q_{z}\right) \Rightarrow \min , z \in Z, \\
& S_{n e t} \Rightarrow \min , \\
& E_{k}\left(C_{k y}\right) \Rightarrow \min , k \in K, y \in Y, \\
& R_{j}\left(v_{j}, \mu_{\mathrm{j}}\right) \Rightarrow \max , j \in J,
\end{aligned}
$$

where $\gamma$ is objective function of a multi-criteria problem of optimizing the structure of heat sources, 
which can be represented by a set of criteria (2-5); $S_{z}$ is cost of source $z$, USD; $Q_{z}$ is heat capacity of a source $z$, Gcal/year; $S_{n e t}$ are cost of the heat network, USD; $E_{k}$ is level of air pollution of a city Which is determined as the sum of the concentrations $C_{k y}$ of the pollutant $k$ at a point of the grid cell superimposed on the city plan; $R_{j}$ is reliability indicators of equipment items for all consumer nodes $j \in J ; v_{j}$ is availability factor; $\mu_{j}$ is probability of uptime.

The problem (1-5) is solved subject to a number of constraints, the most important of which are:

- urban

$$
Q^{\text {city }}=\sum_{z}^{Z} Q_{z},
$$

Gcal/year:

- Urban electricity balance, MWh/year: $\sum_{z}^{Z} W_{z}-W^{\text {city }}-W_{\text {out }}^{\mathrm{eps}}+W_{\text {in }}^{\mathrm{eps}}=0$

where $Q^{\text {city }}$ is heat consumption of city, Gcal/year; $W_{z}$ is electricity supply from source $z$, $\mathrm{MWh} /$ year; $W^{\text {city }}$ is electricity consumption of city, MWh/year;

- Compliance with the standards for maximum permissible emissions (MPE) of harmful substances, t/year:

$$
F_{z k} \leq F_{z k}^{\max }
$$

where $F_{z k}$ is gross emission of harmful substance $k$ of heat source $z, \mathrm{t} /$ year; $F_{z k}^{\max }$ is MPE of harmful substance $k$ into atmosphere, established by calculation for a heat source, t/year.

The problem of multi-criteria optimization of urban heat belongs to problems of the schemestructural optimization which are difficult to formalize and they have non-linear, discrete character. It determines the types, locations, and composition of heat source equipment andis closely linked with the problem of scheme-parametric optimization, since the composition of sources and their relationship with existing or new consumers determine the configuration of the heating network.

\section{METHODS OF MULTICRITERIAL OPTIMIZATION}

The problem can be solved by various analytical methods of multi-criteria optimization. The most wellknown among them are: the method of weight coefficients, the method of assignment, the method of $\varepsilon$-constraints. For comparison of these methods see the Table 1 [11]. The most adapted to the problem are the method of weight coefficients and the method of $\varepsilon$ constraints.

The first one is based on the assignment to each particular criterion of a weighting factor determining its relative importance. All criteria multiplied by their weights are added to form a single scalar optimal criterion, by which further optimization is performed. The disadvantage of the method is the complexity of the distribution of weights.

The $\varepsilon$-constrained method makes it possible to reduce the problem to a single-criterion optimization while not requiring the orderliness of the criteria for their importance and necessity of their normalization. The $\varepsilon$-constraint method is based on identifying the most important particular criterion by which further optimization is performed, and the limitations of the other criteria are constants. When using this method, it is necessary to know the values of these constants.

TABLE I. COMPARISON OF ANALYTICAL METHODS OF MULTI-CRITERIA OPTIMIZATION

\begin{tabular}{|l|l|l|l|}
\hline \multicolumn{1}{|c|}{$\begin{array}{c}\text { Comparison } \\
\text { criterion }\end{array}$} & $\begin{array}{c}\text { Weighte } \\
\text { d sum } \\
\text { method }\end{array}$ & $\begin{array}{c}\text { e-constraint } \\
\text { method }\end{array}$ & $\begin{array}{c}\text { Method of } \\
\text { assignment }\end{array}$ \\
\hline $\begin{array}{l}\text { Using relative } \\
\text { importance criteria }\end{array}$ & + & - & + \\
\hline $\begin{array}{l}\text { Reduction to a } \\
\text { single-criterion } \\
\text { problem }\end{array}$ & + & + & - \\
\hline $\begin{array}{l}\text { Required to } \\
\text { normalize criteria }\end{array}$ & + & - & + \\
\hline $\begin{array}{l}\text { Required ordering } \\
\text { criteria }\end{array}$ & - & - & + \\
\hline
\end{tabular}

The disadvantage of this method is the difficulty of choosing the maximum allowable values of constants [12].

The decomposition method is proposed to solve the problem. It divides the problem (1-8) into two sub problems which are solved by multi-criteria optimization method. The first sub problem is a selection of the optimal composition and parameters of heat sources, the second one is reducing atmospheric pollution by selecting the ways of atmosphere protection at heat sources. The following is description of these sub problems.

\section{SUB PROBLEM 1. SELECT THE OPTIMAL COMPOSITION AND PARAMETERS OF HEAT SOURCES}

The method of weight coefficients has been used for the choice of the composition and main parameters of heat sources . Its own coefficient is assigned to each criterion of the task Here it is the unit values of the discounted costs. The mathematical formulation of sub problem 1 is the sane as in the paper [4].

Set of sources $Z$ of a city consists of existing sources $Z_{1}$ and new sources $Z_{2}$. For each energy source $z \in Z$ set $M_{z}$ is formed where every element $m$ describes a variant of existing heat source of 
reconstruction and/or modernization or a newly installed heat source.

The objective function is the sum of the costs determined by the composition, type and performance of the system elements, USD:

$$
\begin{gathered}
S=\sum_{z}^{Z} s_{z} \cdot Q_{z}+S_{n e t}+\sum_{k}^{K} S_{k} \cdot F_{z k}- \\
-S_{\text {out }}^{e p s} \cdot W_{\text {out }}^{e p s}+S_{\text {in }}^{e p s} \cdot W_{\text {in }}^{e p s} \Rightarrow \min
\end{gathered}
$$

where $S$ is cost of the heat supply system of a city, USD; $s_{z}$ is unit cost of source , USD/Gcal $(\mathrm{USD} / \mathrm{kW}) ; S_{k}$ is penalty for exceeding MPE of substance $k, \mathrm{USD} / \mathrm{t} ; S_{\text {in }}^{\text {eps }}$ is cost of electricity purchased from electric power system, USD/kWh; $S_{\text {out }}^{\text {eps }}$ is cost of electricity saled to power system, $\mathrm{USD} / \mathrm{kWh} ; W_{i n}^{e p s}$ is volume of electricity purchased from electric power system, MWh/year; $W_{\text {out }}^{\text {eps }}$ is the volume of electricity sold to the power system, MWh/year.

The constraints are

$$
\begin{gathered}
Q^{\text {city }}=\sum_{z}^{Z} Q_{z} \\
\sum_{z}^{Z} W_{z}-W^{\text {city }}-W_{\text {out }}^{\mathrm{eps}}+W_{\text {in }}^{\mathrm{eps}}=0,
\end{gathered}
$$

The condition of competition among options of reconstruction and/or modernization of existing heat source $z \in Z_{1}$ is:

$$
\sum_{m}^{M_{z}} V_{z}^{m}=1
$$

The condition of competition among options for each new heat source $z \in Z_{2}$ is:

$$
\sum_{m}^{M_{z}} V_{z}^{m}=G_{z}
$$

where $V_{z}^{m}$ determines the implementation/nonimplementation of an option of equipment $m \in M_{z}$ of a heat source $z$, that has a certain set of technical and economic characteristics; $G_{z}$ is Boolean type variable.

Urban heat supply system should meet the standards of the protection of atmosphere: the maximum MPE of harmful substances, $t$ /year:

$$
F_{z k} \leq F_{z k}^{\max }
$$

Requirements of reliability, which are determined by standard values:

- Availability factor:

$$
v_{j} \geq v_{N},
$$

- Probability of uptime:

$$
\mu_{j} \geq \mu_{N}
$$

where $v_{N}$ is standard availability; $\mu_{N}$ is standard probability of uptime.

For optimal distribution of costs among heat sources and heat networks sequential optimization is organized, i.e. the optimization problem of choosing the parameters of the heat networks is solved for each variant of city's heat sources which corresponds to the minimum cost of their construction and operation for a given configuration:

$$
S_{n e t}=f(\mathbf{d}, \mathbf{x}) \Rightarrow \min
$$

where $\mathbf{d}, \mathbf{x}$ are the vectors of diameter and the heat flow rate in consumer nodes, respectively.

The third component in the function (9) does not fully reflect the goal since the charge for emissions into atmosphere corresponds to the charge for environmental damage, which does not reduce the negative impact of HSS objects on atmospheric pollution. Therefore, there is a need to solve the second sub problem, that is to reduce atmospheric pollution by selecting the MPA at heat sources.

\section{SUB PROBlem 2. CHOICE OF APM}

The problem of choice of atmosphere protection measures has been solved by the $\varepsilon$-constraints method. Here we choose the level of pollution of atmosphere as the most important criterion with the cost as constants. In other words, by setting fixed values of discounted costs for each level of polution, the optimal composition of the APM at the heat sources is selected.

Here the constants will be the values of the net discounted costs of flue gas cleaning equipments. The minimum pollution of the surface layer of the atmosphere will be found for each such value [13]. In more detail, the algorithm of the proposed method is as follows.

An effective set of options for flue gas cleaning equipment for heat sources $A_{u}^{o p t}$ at a certain given level of costs $S_{i}$ is determined by optimizing the distribution of costs of measures for all heat sources using the following algorithm:

1. Set the bounds of allowable costs $\left(S_{\min }, S_{\max }\right)$, where $S_{\max }=\sum_{z=1}^{Z} \sum_{m=1}^{M_{z}} S\left(V_{z}^{m}\right)$ is the upper cost limit, 
$S\left(V_{z}^{m}\right)$ is the cost for option $V_{z}^{m}, S_{\min }>0$ is the lower cost limit ( $S_{1}=\min$ and $S_{U}=\max$, Fig.1).

2. A set of cost values is given $S_{u}^{*}$ : $S_{u-1}^{*} \leq S_{u}^{*} \leq S_{u+1}^{*}, u=\overline{1, \ldots, U}$, for which the optimal set of options $A_{u}^{o p t}$ is determined by the pollutant $k$ at all heat sources of city (Fig. 1).

3. The problem of minimizing the level of pollution of the surface layer of atmosphere corresponding to pollutant $k$ at a given limit of costs $S_{u}^{*}$ is solved and completed a set of options for flue gas cleaning equipment for heat sources:

$$
\begin{gathered}
E_{k}\left(C_{k y}\right)=\sum_{y=1}^{Y_{k}} E_{k y} \Rightarrow \min , \\
C_{k y}-\Delta C_{k y} \leq C_{k}^{\max }, \\
A=\left\{V_{z}^{m}\right\}, z \in Z_{1}, m \in M_{z},
\end{gathered}
$$

provided, that $S(A) \leq S^{*}$,

where $E_{k}=\sum_{y=1}^{Y_{k}} C_{k y}(A) ; A$ is one of the possible options for cleaning equipment of urban heat sources; $C_{k}^{\max }$ is maximum concentration of substance $\mathrm{k}$ in the atmosphere at the territory under consideration, which is relatively safe for population and environment (usually the MPC values established in legislation are taken as sanitary and hygienic standard), $\mathrm{mg} / \mathrm{m}^{3} ; C_{k y}$ is calculated concentration of harmful substance $k$ in atmosphere at point $y, \mathrm{mg} / \mathrm{m}^{3} ; y$ is point from set $Y_{k}$ of points of the territorial dispersion of harmful substance $k ; \Delta C_{k y}$ is change as a result of implementation of option $m$ for source $z, \mathrm{mg} / \mathrm{m}^{3}$.

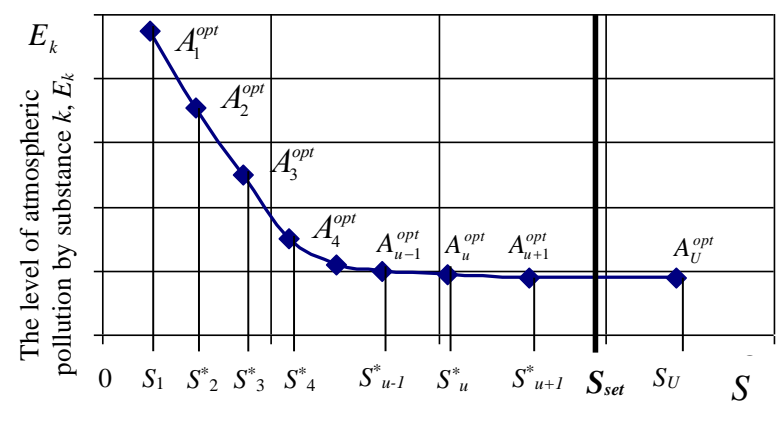

Discounted costs, $\mathrm{S}$

Fig. 1. Curve of the rational distribution of costs across sets of options for flue gas cleaning equipment for heat sources and a decrease in the concentration of the $k$-th pollutant.
As the result we obtain the best option $A_{u}^{o p t}$ for all heat sources and build a dependency curve $E_{k}=f\left(S^{*}\right)$ (Fig. 1). The nearest set of options for cleaning equipment for heat sources is selected for a certain value of allocated costs $S_{\text {set }}$ (costs of which are less than or equal to specified).

Problem (18)-(21) is solved for each pollutant $k$ using dynamic programming methods. Next, lists of the resulting effective sets of cleaning equipment options for heat sources are compiled. For each option of the development and reconstruction of urban HSS, a single set of options for flue gas cleaning equipment for heat sources at a given level of costs given by a researcher is compiled.

\section{METHODICAL APPROACH TO OPTIMIZATION}

To solve the problem described above, a methodical approach consisting of two stages is proposed. The first stage is the solution of the problem of selection the composition and main parameters of the heat sources is solved (Fig. 2, stage 1).

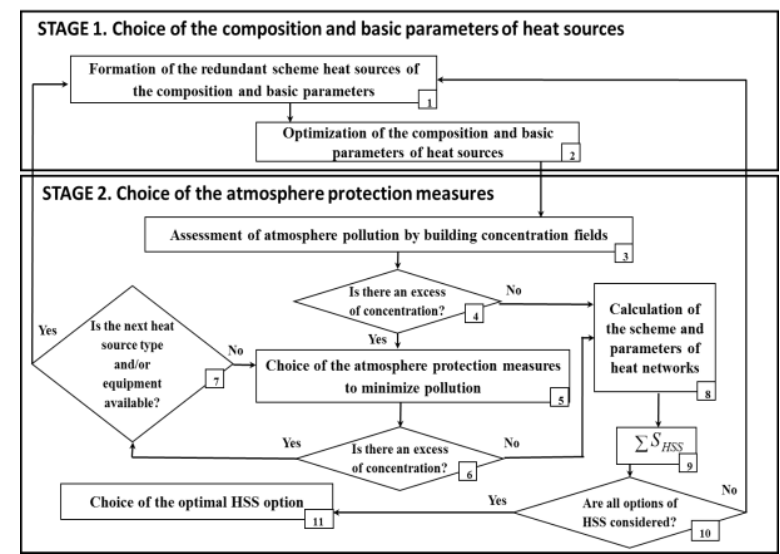

Fig. 2. Scheme of approach to optimization of HSS at the level of urban areas

At the second stage, the problem of the choice of the APM is solved (Fig. 2, stage 2). It consists of the formation of the redundant scheme (block 1) and its optimization (block 2) of the estimation of level of atmospheric pollution (block 3 ) and of construction of the concentration fields and the selection of APM (block 5).

If the concentration of harmful substances is not reduced, return to block 5 or to stage 1 . The type, composition and power of the main or auxiliary equipment can be corrected. Next, a transition is made to blocks 8-11. If the condition is fulfilled the iterative process between the two stages allows to choose several options of the development of HSS and choose the best one.

\section{PRACTICAL APPLICATION OF THE PROPOSED METHODICAL APPROACH}

A practical study of The proposed methodological approach has been applied to a real HSS of a city with 
a population of 13,000 people, the number of heat sources is 51 , the length of heat networks is about 17.7 $\mathrm{km}$, the load of consumers is $27.4 \mathrm{Gcal} / \mathrm{h}$.

The main problems of its functioning are connected with the low quality of the city's heat supply from the central boiler (CB) and with outdated equipment in municipal and industrial boilers.

Concentrations of the total value of ash, $S O_{x}$ exceed the maximum MPC [14-18].
The following scenarios of HSS development have been cosidered: bringing the HSS from the CB to the normal level of operation (reconstruction of heat network and possible limitations of the radius of heat supply from the $\mathrm{CB}$ by installing two small local boilers (LB) on gas near end consumers).

TABLE II. FORMATION OF POSSIBLE OPTIONS FOR THE DEVELOPMENT OF URBAN HSS

\begin{tabular}{|c|c|c|c|c|c|c|c|}
\hline \multirow[b]{2}{*}{ No } & \multirow[b]{2}{*}{$\begin{array}{l}\text { Scenarios for the } \\
\text { development of HSS }\end{array}$} & \multicolumn{6}{|c|}{ Measures } \\
\hline & & Options for the CB & Options for the heat networks & 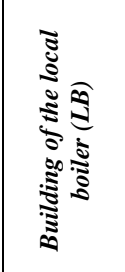 & 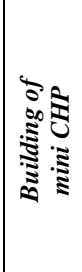 & 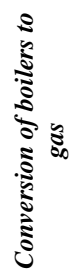 & 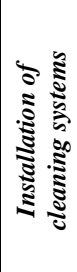 \\
\hline 1 & $\begin{array}{l}\text { Gas-coal (the reconstruction of } \\
\text { heat network and closed } \\
\text { system of hot water } \\
\text { supply(HWS) }\end{array}$ & $\begin{array}{l}\text { Turbine units PROM + } \\
\text { gas conversion }\end{array}$ & $\begin{array}{l}\text { CB: The reconstruction and } \\
\text { adjustment of heat network, } \\
\text { installation of heat station, } \\
\text { temperature chart of the heat } \\
\text { network is } 115 / 70 \text {, the close system } \\
\text { of HWS }\end{array}$ & - & + & + & + \\
\hline 2 & $\begin{array}{l}\text { Gas-coal (the adjustment heat } \\
\text { network) }\end{array}$ & $\begin{array}{l}\text { Turbine units PROM + } \\
\text { gas conversion }\end{array}$ & $\begin{array}{l}\text { CB: The adjustment of heat } \\
\text { network, installation of heat } \\
\text { station, temperature chart of the } \\
\text { heat network is } 115 / 70 \text {, the open } \\
\text { system of HWS }\end{array}$ & - & + & + & + \\
\hline 3 & $\begin{array}{l}\text { Coal-oil (the reconstruction of } \\
\text { the heat network and } \\
\text { installation of the pumping } \\
\text { station) }\end{array}$ & $\begin{array}{l}\text { PROM turbine units }+ \\
\text { oil operation }\end{array}$ & $\begin{array}{l}\text { CB: The reconstruction and } \\
\text { adjustment of heat network, the } \\
\text { installation of the pumping station, } \\
\text { temperature chart of the heat } \\
\text { network is } 95 / 70 \text {, the open system } \\
\text { of HWS }\end{array}$ & - & - & - & + \\
\hline 4 & $\begin{array}{l}\text { Coal-oil (the reconstruction of } \\
\text { the heat network ) }\end{array}$ & $\begin{array}{l}\text { PROM turbine units + } \\
\text { oil operation }\end{array}$ & $\begin{array}{l}\text { CB: The reconstruction and } \\
\text { adjustment of heat network, } \\
\text { temperature chart of the heat } \\
\text { network is } 95 / 70 \text {, the open system } \\
\text { of HWS }\end{array}$ & - & - & - & + \\
\hline 5 & $\begin{array}{l}\text { Gas-coal (the building of the } \\
\text { LB №1) }\end{array}$ & $\begin{array}{l}\text { Turbine units PROM + } \\
\text { gas conversion }\end{array}$ & $\begin{array}{l}\text { CB: The adjustment of heat } \\
\text { network, installation of heat } \\
\text { station, temperature chart of the } \\
\text { heat network is } 115 / 70 \text {, the open } \\
\text { system of HWS }\end{array}$ & LB 1 & + & + & + \\
\hline 6 & $\begin{array}{l}\text { Gas-coal (the building of the } \\
\text { LB } 1 \text { and the connection of } \\
\text { utility consumers) }\end{array}$ & $\begin{array}{l}\text { Turbine units PROM + } \\
\text { gas conversion }\end{array}$ & $\begin{array}{l}\text { CB: The adjustment of heat } \\
\text { network, installation of heat } \\
\text { station, temperature chart of the } \\
\text { heat network is } 115 / 70 \text {, the open } \\
\text { system of HWS LB 1: the laying of } \\
\text { heat networks }\end{array}$ & $\begin{array}{l}\text { LB 1, } \\
\text { the } \\
\text { connecti } \\
\text { on of } \\
\text { utility } \\
\text { consume } \\
\text { rs }\end{array}$ & + & + & + \\
\hline 7 & $\begin{array}{l}\text { Gas-coal (the closed system of } \\
\text { the hot water supply and } \\
\text { building of LB 2) }\end{array}$ & $\begin{array}{l}\text { Turbine units PROM + } \\
\text { gas conversion }\end{array}$ & $\begin{array}{l}\text { CB: The reconstruction and } \\
\text { adjustment of heat network, } \\
\text { installation TП, temperature chart } \\
\text { of the heat network is } 115 / 70 \text {, the } \\
\text { close system of HWS }\end{array}$ & LB 2 & + & + & + \\
\hline 8 & $\begin{array}{l}\text { Gas-coal-oil (conversion of } \\
\text { only the central boiler to gas, } \\
\text { the building of LB } 1 \text { and } \\
\text { connection of utility } \\
\text { consumers) }\end{array}$ & $\begin{array}{l}\text { Turbine units PROM + } \\
\text { gas conversion }\end{array}$ & $\begin{array}{l}\text { CB: The adjustment of heat } \\
\text { network, installation of heat } \\
\text { station, temperature chart of the } \\
\text { heat network is } 115 / 70 \text {, the open } \\
\text { system of HWS LB 1: the laying of } \\
\text { heat networks }\end{array}$ & $\begin{array}{l}\text { LB 1, } \\
\text { the } \\
\text { connecti } \\
\text { on of } \\
\text { utility } \\
\text { consume } \\
\text { rs }\end{array}$ & - & - & + \\
\hline
\end{tabular}


The correspoding calculations have been performed on special models of hydraulics and reconstruction of heat networks [19] in the laboratory of HSS of the SEI SB RAS. The reconstruction included the construction of mini CHP at boiler based on a gas turbine unit (GTU); installation of a gas generator (GGU), working on waste flax; installation of PROM turbines on the $\mathrm{CB}$ in order to use pressure drop to generate electricity.

According to the scenarios of HSS development (Table 2) 8 strategic directions of city HSS development were compiled. For them the calculations were carried on a software-computer complex using the method proposed above [15]. The results are presented in Fig. 3 as a diagram of costs for the reconstruction and development of HSS for two methods for calculating surface concentrations of harmful substances: "CMD-2017" [16] and a methodology "Berland" based on Berland's theory [17, 18 ] depending on their environmental compatibility.

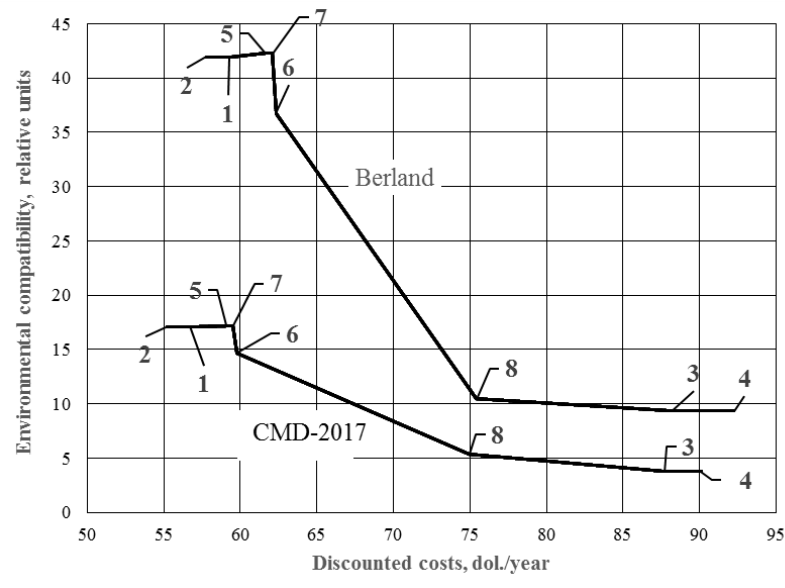

Fig. 3. Dependence of the environmental compatibility from HSS development options for the total discounted costs for the two methods for calculating surface concentrations

Environmental compatibility of each variant of HSS development is a difference of values before the realization of this variant and after its realization.

The "coal, oil" scenarios have the lowest environmental compatibility (Fig. 2, scenarios 3, 4, 8), and installing cleaning equipment at a number of boilers reduces to the level of the concentration only the emission of ash, keeping the excess $S O_{x}$. Full compliance with the norms of maximum permissible concentrations for harmful substance emissions is provided only "gas" scenarios (Fig. 2, options 1, 2, 5, $6,7)$.

Note also that the "coal, oil" scenarios are characterized by high costs for the operation of heat sources (high tariffs for liquid fuel and purchased electricity, low fuel efficiency).

\section{VIII.CONCLUSIONS}

1. The multi-criteria problem of choosing the heat source structure in heat supply systems is formulated. Its solution provides reliable and safe heat supply of consumers and minimal impact of heat supply systems on the environment.

2. The methods of multi-criteria optimization are proposed: the method of weighted sum and $\varepsilon$ constraint method, both allow to reduce the presented problem to single-criterion one .

3. The stated multi-criteria problem has been decomposed into two ones: the choice of the main equipment of heat sources and the choice of atmosphere protection measures. These problems are linked to each other in a single iterative process.

4. Calculations of the development of real heat supply systems showed the efficiency of the proposed approach.

\section{ACKNOWLEDGMENT}

Results are obtained as a part of project of government contract ESI SB RAS III.17.4.1 (No. AAAA-A17-117030310432-9).

\section{REFERENCES}

[1] Federal Law of 21.07.2011 No. 256 "On the safety of objects of the fuel and energy complex". 23 p. [Online]. Available: http://www.kremlin.ru/acts/bank/33689/page/1 Accessed on: Mar. 31, 2019. [In Russian].

[2] Federal Law of 10.01.2002, No. 7-FZ "On Environmental Protection". 48 p. [Online]. Available: https://fzakon.ru/laws/federalnyy-zakon-ot-10.01.2002-n-7-fz/ Accessed on: Mar. 31, 2019. [In Russian].

[3] N.I. Voropai, V.A. Stennikov, E.A. Barakhtenko, Methodological principles of constructing the integrated energy supply systems and their technological architecture, In Journal of Physics: Conference Series, vol. 1111, No. 1, p. 012001, December 2018.

[4] Edeleva, Olga, and Valery Stennikov, "Optimization of energy sources structure to minimize environment pollution", In E3S Web of Conferences, vol. 69, p. 02007, 2018.

[5] L. Wang, Z. Yang, S. Sharma, A. Mian, T.E Lin, G. Tsatsaronis, F. Maréchal and Y. Yang, A Review of Evaluation, Optimization and Synthesis of Energy Systems: Methodology and Application to Thermal Power Plants. Energies, vol.12(1), p.73, 2019.

[6] S. Goderbauer, B. Bahl, P. Voll, M.E. Lübbecke, A. Bardow and A.M. Koster, An adaptive discretization MINLP algorithm for optimal synthesis of decentralized energy supply systems. Computers \& Chemical Engineering, vol. 95, pp.38-48, 2016.

[7] N.I. Voropay, S.V. Podkovalnikov, V.V. Trufanov et al, Justification of the development of electric power systems: Methodology, models, methods, their use, Novosibirsk, Russia: Science, 2015. [In Russian].

[8] S. Goderbauer, M. Comis, and F.J. Willamowski, The Synthesis Problem of Decentralized Energy Systems is strongly NP-hard, Computers \& Chemical Engineering, 2019, in press.

[9] M. Carvalho, M.A.Lozano, and L.M. Serra, Multicriteria synthesis of trigeneration systems considering economic and environmental aspects. Applied Energy, vol. 91(1), pp.245254, 2012.

[10] D. Atabay: An open-source model for optimal design and operation of industrial energy systems, Energy, vol. 121, pp. 803-821, 2017.

[11] D.A. Moskvin, M.O. Kalinin. Prospects for the use of multicriteria optimization in managing the security of information systems, Reports of TUSUR, part 1, no. 2, pp. 128-129, 2008. [In Russian].

[12] I.G. Zakharov, Justification of the choice. Theory of practice, St. Petersburg, Russia: Shipbuilding, 2006. [In Russian]. 
[13] A.M. Bronstein, V.A. Litvin, I.I. Rusino Greening the economy: methods of regional management, Moscow, Russia: Science, 1990. [In Russian].

[14] Protection of the atmosphere from industrial pollution, part 1, Moscow, Russia: Metallurgy, 1988. [In Russian].

[15] O.A. Baranova, "Methodical approach to the improvement of heat supply systems, taking into account atmospheric protection measures" Ph.D. dissertation, ESI SB RAS, Irkutsk, Russia, 2004. [In Russian].

[16] Calculation methods for the dispersion of harmful substances emissions of atmospheric air. Approved by order of the Ministry of Natural Resources of Russia, June 6, 2017. [Online]. Available: http://docs.cntd.ru/document/456074826 Accessed on: Mar. 31, 2019. [In Russian].

[17] E.V. Kazimirovskaya, S.V. Kozlov Mathematical model for the transfer of CPP emissions in the local zone, Materials of the 24th scientific youth conference of SEI SB RAS, Irkutsk, Russia: SEI SB RAS, pp. 20-25, 1994. [In Russian].

[18] Climatic characteristics of the conditions of distribution of impurities in the atmosphere: Handbook, Leningrad, USSR: Hydrometeoizdat, 1983. [In Russian].

[19] N.N. Novitsky, E.V. Sennova, M.G. Sukharev et al., Hydraulic chains. Development of the theory and application, Novosibirsk, Russia: Science, 2000. [In Russian]. 